\title{
Effects of Activities of Daily Living (ADL) Instructions on Patient with Osteoarthritis of the Knee
}

\author{
MD. GOLAM NOBI, ${ }^{1}$ ABUL KALAM AZAD, ${ }^{2}$ BADRUNNESSA AHMED, ${ }^{3}{ }^{2 M A M U R ~ R A S H I D, ~}{ }^{4}$ TARIQUL ISLAM, $^{5}$ MA SHAKOOR ${ }^{6}$
}

\begin{abstract}
:
This prospective experimental study was done in the Department of Physical Medicine and Rehabilitation, Bangabandhu Sheikh Mujib Medical Universiry, Dhaka from Ist January 2008 to $3 I^{\text {st }}$ July 2008 to observe the effects of $A D L$ instructions on patients with osteoarthritis of the knee. A total of 60 patients with $O A-$ knee were selected. Out of 60 patients $28(46.7 \%)$ were female and $32(53.3 \%)$ were male. The female to male ratiol.I4:I. Age distribution varied from $>40$ years to $<70$ years with a mean age was $53.58 \pm 6.86$ years. Maximum patients $17(28.3 \%)$ belonged to age group of $56-60$ years in both sexes and house wives were maximum in number 26 (43.3\%). They were divided into two groups, 30 patients treated with therapeutic exercise plus NSAID and another 30 patients were with therapeutic exercise, NSAID and $A D L$. In both groups patients were treated for six weeks. In the present study, the group of patients who received NSAID, Exercise and ADL instructions improved more significantly than those who were not advised ADL instructions but received NSAID and exercise only (95\% Cl: 4.30 to $9.36, \mathrm{P}=0.00 \mathrm{I})$. So, from the present study it may be concluded that activities of daily living instructions play a role to improve the symptoms of $O A$ knee.
\end{abstract}

Keyword: OA (Osteoarthritis), ADL (Activities of daily living), WOMAC (Western Ontario and McMaster Universities) index.

\section{Introduction:}

Osteoarthritis (OA) is a degenerative disorder of synovial joint in which there is progressive destruction of articular cartilage accompanied by juxtra-articular new bone formation and remodeling. ${ }^{1}$ Osteoarthritis (OA) is the most common form of arthritis, affecting million of people in the United States. ${ }^{2}$ Patients with Osteoarthritis have pain that typically worsens with weight bearing and activity and improves with rest, as well as morning stiffness and gelling of the involved joint after periods of activity. Although there is no known cure for OA, treatment designed for the individual patient can reduce pain, maintain and improve joint mobility and limit functional impairment.

Osteoarthritis is a common disorder in all population, while the overall prevalence is about the same in men and women. There is a more rapid age related increase in the prevalence of generalized OA in women than in men. ${ }^{3}$ By the age 40, $90 \%$ of all persons have such changes in their weight bearing joints, even though clinical symptoms are generally absent. ${ }^{4}$
Men and women were equally affected by OA in one study when all ages were considered. ${ }^{5}$ Under age 45 , prevalence was greater among men, where prevalence was greater in women than in men after age 55.Moderate and severe grades of OA were seen to a greater extent in women than in men. ${ }^{6}$ Obesity is closely associated with development of knee osteoarthritis. Other studies have demonstrated an increase frequency of $\mathrm{OA}$ in the obese, particularly in weight bearing joint. ${ }^{7}$ Stress related to occupation or sports activity has been implicated in the induction of OA. In one study, OA of hips, knees and shoulders were more common in miners than in porters. Dock workers showed a higher prevalence of OA in the fingers, elbows and knees than age matched civil servants. ${ }^{8}$

The treatment must be individualized to the needs of the given patient. A new approach to management is emerging, with emphasis on comprehensive programs of patient education, drugs, non medicinal, non surgical treatments, including superficial and deep heat, cold, general and specific

1. Medical Officer, Dept. of Physical medicine \& Rehabilitation, BSMMU, Dhaka, Bangladesh

2. Medical Officer, Dept. of Physical medicine \& Rehabilitation, BSMMU, Dhaka, Bangladesh

3. Medical Officer, Dept. of Physical medicine \& Rehabilitation, BSMMU, Dhaka, Bangladesh

4. Medical Officer, Dept. of Physical medicine \& Rehabilitation, BSMMU, Dhaka, Bangladesh

5. Medical Officer, Dept. of Physical medicine \& Rehabilitation, BSMMU, Dhaka, Bangladesh

6. Associate Professor, Dept. of Physical medicine \& Rehabilitation, BSMMU, Dhaka, Bangladesh

Correspondance: Dr. Mohammad Golam Nobi, Dept. of Physical Medicine \& Rehabilitation, BSMMU, Dhaka, Bangladesh. E-mail: dr.golamnobiazad@yahoo.com 
exercises, weight loss, acupuncture, transcutaneous electrical nerve stimulation, low energy laser, vibration, topically applied creams, pulsed electromagnetic fields, orthotic devices, psychosocial intervention and surgery. Education is very important to instill a positive attitude where patients are prepared to help themselves. Tips on "joint protection" and the use of simple aids such as walking stick are usually included and obese patients are generally advised to lose weight. In the absence of disease specific treatment, the main aims are relief of symptoms with low risk treatment, minimizing handicap through rehabilitation and trying to limit progression by avoidance of aggravating factors. In particular meloxicam's superior gastric tolerability over diclofenac, naproxen and piroxicam has been established from a ruta analysis metaanalysis of studies included in the clinical development program. ${ }^{9}$ Furthermore, it remains to be seen whether new Cox 2 inhibitors will be adequately effective NSAIDs and safe for the kidneys. ${ }^{10}$ Many other nonpharmacological options are available for the treatment of OA knee. Such as weight reduction hydrotherapy, footwear, walking aids, patients education, activity modification, ADL training, exercise, aerobic activities etc. ${ }^{11-15}$ In the present study we treated patients with ADL instructions to reduce the disability \& to improve the functional capability of the patients with OA knee and to decrease use of NSAIDS.

\section{Methodology:}

A prospective experimental study was done in the Department of Physical Medicine \& Rehabilitation, Bangabandhu Sheikh Mujib Medical University, Dhaka, during the period of January 2008 to June 2008. A total of 60 (sixty) patients were included in the study with the following selection criteria. Inclusion criteria:- Patients aged $>40$ years and $<70$ years of age with primary Osteoarthritis, Patients with primary Osteoarthritis and Duration of symptoms more than 3 months. Exclusion Criteria:- Patients Aged $<40$ years and $>70$ years, Patients with Secondary Osteoarthritis and Patients with malignant disease or infection. They were divided in to two groups randomly by the way of lottery. Group- A (Control group) who were given only NSAID + Exercise \& Group -B (Study group) who were given NSAID + Exercise + ADL instructions. In GroupA NSAID (Aceclofenac 100mg bid) with Omeprazole (20mg) bid and Quadriceps strengthening exercise 10 repetitions two times daily were given. In Group-B, ADL instructions was added along with the treatment which was given to the Group-A.

ADL instructions were as follows: 1. Do not walk or Jog as an exercise, swimming can be taken as an alternative. 2. Avoid stairs whenever possible.3. Sit rather than stand. Use a high stool when working at a counter.4. Use higher chair rather than low sofas.5. Avoid kneeling or squatting. 6. Use walking stick on the opposite hand during walk. 7. Use knee cap/ brace during walk. 8 . Before arising from a chair, sit at the edge of the seat with legs under the body. Use the armrests to push up from the seat. 9. Use a pair of jogging shoes with well cushioned soles as primary foot wear, orthotic supports (e.g. wedge insoles for varus or valgus knee deformities). 10. Reduce body weight if over weight.

Each group was assessed every 7 days interval. There were 6 visits and in each visit patients were assessed for pain, stiffness and physical function by WOMAC (Western Ontario and McMaster Universities) index. The WOMAC index consists of 24 questions ( 5 for pain, 2 for stiffness and 17 for physical functions). The numerical data were analyzed statistically. The results were expressed as mean \pm SD and the level of significance was by P-value unless otherwise stated. Student's ' $t$ ' test was done to see the level of significance.

\section{Results:}

Out of sixty patients thirty two were female and twenty eight were males. Female to male ratio was 1.14:1. Percentage of female and male were $53.3 \%$ and $46.7 \%$ respectively. All the cases were managed as out patients. The age range of the patients in the study varied from aged $>40$ to $<70$ years in respective of both sexes. The mean age of the patients of both sexes was $53.58 \pm 6.86$ years. Out of total 60 patients irrespective of sexes it was observed that most patients that is $17(28.3 \%)$ belonged to age group of 56 to 60 years (TableI). Regarding occupation, maximum patients were house wives $(43.3 \%)$. Then we found businessman $(16.7 \%)$ and serviceman $(16.7 \%)$. We also found teachers, retired serviceman and house maids (Table-II). There was significant improvement after treatment in group A. In respect to time point improvement, marked improvement was started to occur after one week. ( $\mathrm{p}=0.001,95 \% \mathrm{CI}=2.65$ to 8.21$)$ and the improvement gradually increases day by day. And after the end of treatment there was significant improvement ( $\mathrm{p}=0.001$, $95 \% \mathrm{CI}=15.03$ to 20.50 Table-III). This indicates that treatment with exercise plus NSAIDs is effective for improvement of OA knee joints. There was significant improvement after treatment in group B also. In respect to time point improvement, marked improvement started to occur after one week ( $\mathrm{p}=0.001,95 \% \mathrm{CI}=12.33$ to 17.46$)$ and the improvement gradually increases day by day. And after the end of treatment there was significant improvement found in our study that the $\mathrm{W}_{1 \text { vs }} \mathrm{W}_{6} \quad(\mathrm{p}=0.001,95 \% \mathrm{CI}=20.76$ to 26.30 Table -IV ).This indicates that treatment with exercise plus NSAIDs plus ADL is effective for improvement of OA knee joints. In comparison between two groups it was found that there was significant improvement in the group taking ADL instructions (Group-B) after one week. More improvement was found after $3^{\text {rd }}$ week $(p=0.001$ and $95 \%$ CI was3.91 to 11.55). Finally it was found that there was significant improvement in Group-B than Group -A after 6 weeks ( $\mathrm{p}=0.001,95 \% \mathrm{CI}$ was 4.30 to 9.36 ). 
Table-I

Age distribution of both male and female patients $(n=60)$

\begin{tabular}{lcc}
\hline Age (Years) & Frequency & Percentage \\
\hline $40-45$ & 9 & 15.0 \\
$46-50$ & 11 & 18.3 \\
$51-55$ & 16 & 26.7 \\
$56-60$ & 17 & 28.3 \\
$61-65$ & 6 & 10.0 \\
$66-70$ & 1 & 1.7 \\
\hline Total & 60 & 100.0 \\
\hline
\end{tabular}

$\mathrm{n}=$ Number of total study subjects
Table-II

Occupational distribution of the study subjects.

\begin{tabular}{lcc}
\hline Occupation & Frequency & Percentage \\
\hline Housewife & 26 & 43.3 \\
Business & 10 & 16.7 \\
Service man & 10 & 16.7 \\
Teacher & 5 & 8.3 \\
Others & 4 & 6.7 \\
Retired & 3 & 5.0 \\
Housemaid & 2 & 3.3 \\
\hline Total & 60 & 100.0 \\
\hline
\end{tabular}

$\mathrm{n}=$ Number of patient included in the study

Table-III

Treatment Response in Group A $(n=30)$ at different time points.

\begin{tabular}{llcc}
\hline Time Points & Mean \pm SD & $95 \%$ CI & P-value \\
\hline $\mathrm{W}_{1 \mathrm{vs}} \mathrm{W}_{2}$ & $35.00 \pm 9.50_{\text {vs }} 29.56 \pm 9.19$ & 2.65 to 8.21 & 0 \\
$\mathrm{~W}_{1 \mathrm{vs}} \mathrm{W}_{3}$ & $35.00 \pm 9.50_{\text {vs }} 25.00 \pm 8.15$ & 6.92 to 11.27 & 0 \\
$\mathrm{~W}_{1 \mathrm{vs}} \mathrm{W}_{4}$ & $35.00 \pm 9.50_{\text {vs }} 22.30 \pm 8.33$ & 10.58 to 14.81 & 0 \\
$\mathrm{~W}_{1 \mathrm{vs}} \mathrm{W}_{5}$ & $35.00 \pm 9.50_{\text {vs }} 19.40 \pm 6.25$ & 13.42 to 17.74 & 0 \\
$\mathrm{~W}_{1 \mathrm{vs}} \mathrm{W}_{6}$ & $35.00 \pm 9.50_{\mathrm{vs}} 17.00 \pm 4.94$ & 15.03 to 20.50 & 0 \\
\hline
\end{tabular}

$\mathrm{SD}=$ standard deviation, $\mathrm{n}=$ number of patients, $\mathrm{W}=$ week.

\section{Table-IV}

Treatment response in Group $B(n=30)$ at different time points.

\begin{tabular}{lllc}
\hline Time Points & Mean \pm SD & $95 \%$ CI & P-value \\
\hline $\mathrm{W}_{1 \text { vs }} \mathrm{W}_{2}$ & $33.76 \pm 9.61_{\text {vs }} 18.86 \pm 7.31$ & 12.33 to 17.46 & 0 \\
$\mathrm{~W}_{1 \text { vs }} \mathrm{W}_{3}$ & $33.76 \pm 9.61_{\text {vs }} 18.86 \pm 7.31$ & 12.33 to 17.46 & 0 \\
$\mathrm{~W}_{1 \text { vs }} \mathrm{W}_{4} \mathrm{~W}_{1 \text { vs }} \mathrm{W}_{5}$ & $33.76 \pm 9.61_{\text {vs }} 14.56 \pm 6.28$ & 16.57 to 21.82 & 0 \\
$\mathrm{~W}_{1 \text { vs }} \mathrm{W}_{6}$ & $33.76 \pm 9.61_{\text {vs }} 12.53 \pm 6.44$ & 18.42 to 24.04 & 0 \\
\hline
\end{tabular}

$\mathrm{SD}=$ standard deviation, $\mathrm{n}=$ number of patients, $\mathrm{W}=$ week.

Table-V

Comparative Improvement of Symptoms between Group-A and Group-B in different time points

\begin{tabular}{lcccccc}
\hline Group & Score at $\mathrm{W}_{1}$ & Score at $\mathrm{W}_{2}$ & ${\text { Score at } \mathrm{W}_{3}}$ & ${\text { Score at } \mathrm{W}_{4}}$ & ${\text { Score at } \mathrm{W}_{5}}{\text { Score at } \mathrm{W}_{6}}$ \\
\hline $\mathrm{A}(\mathrm{n}=30)$ & $35.00 \pm 9.50$ & $29.56 \pm 9.19$ & $25.00 \pm 8.15$ & $22.30 \pm 8.33$ & $19.40 \pm 6.26$ & $17.06 \pm 4.94$ \\
$\mathrm{~B}(\mathrm{n}=30)$ & $33.76 \pm 9.61$ & $18.86 \pm 7.31$ & $18.86 \pm 7.31$ & $14.56 \pm 6.28$ & $12.53 \pm 6.44$ & $10.23 \pm 4.83$ \\
$95 \% \mathrm{CI}$ & -3.70 to 6.17 & 6.40 to 14.90 & 3.02 to 11.03 & 3.91 to 11.55 & 3.58 to 10.15 & 4.30 to 9.36 \\
\hline P-value & 0.619 & .000 & .001 & .000 & .000 & .000 \\
\hline
\end{tabular}

$\mathrm{SD}=$ standard deviation, $\mathrm{n}=$ number of patients, $\mathrm{W}=$ week. 


\section{Discussion:}

In the present study a total of 60 patients of OA knee dully participated in the study. Out of them 32(53.3\%) were female and $28(46.7 \%)$ were male and female to male ratio was 1.14:1.In a study in Chittagong, Bangladesh by Shakoor MA et al it was found that out of 162 patients $66(40.7 \%)$ of the patients were female and $96(40.7 \%)$ were male. Female to Male ratio was $0.68: 1 .{ }^{11}$ It may be for the reason that people in Chittagong are conservative so, female attendance in the hospital is less. Present study would not reflect the incidence due to small number of study population. Felson DT et al. mentioned, female male ratio is 1.58:1 in the Framingham osteoarthritis study. ${ }^{16}$ The female preponderance may be due to more female attendance in hospital than male because male are more busy at work and they may take consultation from private doctors in the evening. In our study the mean age of the patients were $53.58 \pm 6.86$ years. Out of 60 patients in the study most of the patients of OA knee was at the age group 56 to 60 years, seventeen $(28.3 \%)$ were in this group. And then sixteen (26.7\%) patients were in the age group of 51 to 55 years. The lowest group were in the age group of 66 to 70 years, only one (1.7\%) was in this group. In one study in Dhaka the mean age was found to be $52.10 \pm 12.22$. This is to some extend same as the result found in the present series. Felson DT et al. proposed the range between 63 to 94 years. ${ }^{12}$ It is comparatively higher than that of present study as the life expectancy in America is more and their life style is different than that of our country. Most of the patients were house wives (43.3\%) found in our study. In a study in Dhaka it was found that most of the patients of OA knee were housewives (45\%), this is in favour of the finding of the present study. In developing country like Bangladesh, most of the housewives use to do their household work in knee bending position. By these studies it is evident that the housewives have become more conscious about their health. In the present study most of the patients were from the middle class group (85\%). Most of the study subjects came from Dhaka Metropolitan City. In some studies it was found that middle class people attended more in their studies. This same as in our study, this is may be due to poverty situation of our country. Rich people usually take treatment from private clinic and from private doctors. So, they are less in the study. On the other hand, poor are illiterate and do not have enough money to spend to reach the tertiary level hospital. So, they are less in number in our study. The most important finding of the current study is the outcome of the patients with OA knee. The significant improvement of symptoms within both the groups began to appear at the end first week. Significant difference of improvement was found to begin between the groups at this stage.
The trend of improvement continued through out the whole period of six weeks. At the end of $6^{\text {th }}$ week significant improvements of symptoms were found. And in comparison between the two groups the significant improvement was found in the group who received NSAID, Exercise and ADL instructions than those who were not advised ADL instructions but received NSAID and exercise only. In a study in Chittagong, Bangladesh it was found that activity modification in patients with OA knee was beneficial to reduce symptoms which support the present study. ${ }^{11}$ Some authors recommended patients education for the treatment of osteoarthritis. ${ }^{12,13,15}$ This education is also including the instructions of ADLs.

\section{Conclusion:}

Considering the information gathered from this small study, it could be concluded that ADL instructions is helpful for the treatment of OA knee to reduce pain and disability of the patients.

\section{Conflict of Interest : None}

\section{References:}

1. Apley A G, Solomon L. Osteoarthritis. In: Apley's System of Orthopedics and Fractures. $8^{\text {th }}$ edition-2001.

2. Lawrence R C, Helmick C G, Arnett F C, Deyo R A, Felson D T, Giannini E H, et al. Estimates of the prevalence of arthritis and selected musculoskeletal disorders in the United States. Arthritis Rheum 1998; 41:778-99.

3. Snell Richard S. Lower limb in clinical Anatomy for Medical students. Fifth Edition.

4. Muki G. -Disease of connective tissues; bone and joints, Edwards Christopher R.W. and Beuchier Ion A.D. (Ed.), Davidson's Principles and Practice of Medicine 20th Edition.

5. Roberts J. and Burch T.A.; Prevalence of osteoarthritis in adults by age, sex, race and geographic area, United states 1960-1962, National Centre for Health Statistics, Vital and health statistics; Data from the National health survey, series 11, No.- 15, 1960, Washington D.C. USA Government print office.

6. Felson D. Anderson J.J., Naimark A., et. al., Does smoking protect against osteoarthritis, Arthritis Rheum. 1989; 32:162172 .

7. Leach R.E., Baumgard S. and Brooms; obesity; its relationship to osteoarthritis of the knee, clin. Orthop. 1973; 93:271-273.

8. Pontrige R.E.H., and Duthie J.J.R., Rheumatism in Dockers and civil servants, A comparison of handedness and hand use. J. Rheumatol., 1968; 27:559-568. 
9. Carrabba M. Paresca E, et al. A comparison of the local tolerability, safety and efficacy of meloxicam and Piroxicam suppositories in patients with OA Curr Med Res Opin. 1995; 13:343-46.

10. Vane J R. NSAIDs, Cox-2 inhibitors, and the gut. Lancet.1995; 346(8982): 1105-06.

11. Shakoor MA, Taslim MA, Hossain MS. Effects of activity modification on thepatients with osteoarthritis of the knee. Bangladesh Med Res Counc Bull 2007;33:55-59.

12. Felson DT. Osteoarthritis of the knee. N Eng J Med 2006: $354 ; 841-8$.
13. Manek N J, Lane N E. Osteoarthritis: Current concepts in diagnosis and management. Am Fam Physician 2000; 61: 1795-804.

14. Hochberg M C, Altman RD, Brandt K D, Clark Bm, Dippe PA, Griffin MR et al.Guideline for the medical Management of Osteoarthrities. J Am Coll of Rheum 1995: 38; 1541-46.

15. Choudhury M R, Zaman MM, Huq SM, Alam F, Hakim F, Saha PR et al. A Reviewon Osteoarthrities. J Bangladesh Coll Phys Surg 2005; 23:124-136.

16. Felson D T, Naimark A, et al. The Prevalence of knee osteoarthritis in the elderly.The Framingham Osteoarthritis study. Arthritis and Rheum. 1987; 30:8 914-15. 